\title{
Factors affecting the Duration of Surgical Extraction of Impacted Mandibular Third Molars
}

\author{
Salwan Y Bede
}

\section{ABSTRACT}

Aim: The aim of this study is to evaluate the effect of demographic, clinical, and radiographic factors on the duration of surgical extraction of impacted lower third molars.

Materials and methods: This retrospective study included patients who underwent surgical removal of impacted lower third molars, and the investigated factors were demographic data including age and gender, radiographic data including the impacted tooth angulation and depth of impaction and ramus relation, and clinical data including the state of eruption of the impacted teeth. These factors were evaluated for association with the duration of surgery. Descriptive statistical analysis included percentages and mean \pm standard deviation (SD). Student's t-test was used to compare means between two groups, while for comparing the means among three or more groups for statistical significance, analysis of variance (ANOVA) test was used.

Results: Forty patients were included: 20 (50\%) males and 20 $(50 \%)$ females. The age range was from 17 to 37 years with a mean $\pm S D$ of $23.4 \pm 5.016$ years. The duration of surgery $( \pm S D)$ in all the patients ranged from 10 to 40 minutes with a mean of $25.8 \pm 8.56$ minutes. Clinically unerupted teeth and deep ramus relationship were associated with statistically significant increase in duration of surgical extraction.

Conclusion: This study identifies state of eruption and ramus relation to be significant predictive factors, whereas other investigated factors, namely, age of patient, sex, angulation of teeth, and depth of impaction, were found to be not significant in determining the duration of surgery and hence, the difficulty of extraction.

Clinical significance: Duration of surgical extraction of impacted mandibular third molars can be considered as an indicator for difficulty of surgical extraction. Difficult surgical extraction of impacted mandibular third molars can be anticipated in clinically unerupted teeth and those with deep ramus relationship.

Keywords: Duration of surgery, Impacted third molar, Retrospective cohort study, Surgical extraction.

How to cite this article: Bede SY. Factors affecting the Duration of Surgical Extraction of Impacted Mandibular Third Molars. World J Dent 2018;9(1):8-12.

Department of Oral and Maxillofacial Surgery, College of Dentistry, University of Baghdad, Baghdad, Iraq

Corresponding Author: Salwan Y Bede, Department of Oral and Maxillofacial Surgery, College of Dentistry, University of Baghdad, Baghdad, Iraq, Phone: +009647906210006, e-mail: salwan.bede@gmail.com/salwan.bede@codental.uobaghdad. edu.iq

\section{Source of support: Nil}

Conflict of interest: None

\section{INTRODUCTION}

An impacted tooth is defined as the tooth that fails to erupt into the dental arch within the expected time, ${ }^{1}$ and other definitions for impaction have been set forth. ${ }^{2-4}$ The mandibular third molar is the most commonly impacted tooth in the mouth with a prevalence rate that may reach up to $70 \%$ of the population. The main cause of impaction is the lack of space in the dental arches. ${ }^{5,6}$

Surgical removal of impacted lower third molars under local anesthesia is widely carried out in dental practice and continues to be the most common surgical procedure performed by oral and maxillofacial surgeons. ${ }^{7,8}$

Several classifications of impacted third molars have been described. Winter ${ }^{9}$ suggested a classification of the angulation of the third molar based on the relationship of the impacted tooth on the long axis of the second molar. Pell and Gregory ${ }^{10}$ classified the depth of the impaction into two categories: The first identifies the position of impacted tooth according to the second molar, while the second category relates the impacted third molar to the ascending ramus of the mandible. Killey and Kay ${ }^{11}$ classified the state of eruption of impacted third molars into erupted, partly erupted, or unerupted.

Numerous studies have investigated factors that are associated with the surgical difficulty in extraction of impacted mandibular third molars, of which the duration of surgery has been regarded as an important indicator for surgical difficulty and postoperative morbidity. ${ }^{8,12,13}$ Many studies have examined the influence of different factors on the duration of third molar surgery. These factors included demographic factors, such as age, sex, weight, and ethnic groups. Clinical factors and radiographical factors, such as the angulation, depth, root morphology of the impacted teeth and the proximity to the inferior dental canal, and their association with surgical difficulty were also studied, yet there is wide variation in their results and findings. . $^{7,12-14}$

The aim of this study was to evaluate the effect of demographic, clinical, and radiographic factors on the duration of surgical extraction of impacted lower third molars. 


\section{MATERIALS AND METHODS}

This retrospective cohort study included patients who underwent surgical removal of impacted lower third molars at the Department of Oral and Maxillofacial Surgery, College of Dentistry, University of Baghdad, Iraq.

The inclusion criteria were otherwise healthy patients with infection-free impacted third molars at the time of surgery. Patients diagnosed with pathological conditions associated with the impacted teeth, such as cysts or tumors were excluded from this study.

The indications for extraction of mandibular impacted third molars included recurrent pericoronitis, preparation for orthodontic treatment, caries involving the impacted teeth and/or the adjacent mandibular second molars, and periodontal diseases.

For all the patients, a standardized case sheet was completed and orthopantomogram and periapical radiographs were taken.

All the surgical procedures were carried out by the author under local anesthesia (lidocaine $2 \%$ with adrenaline 1:100,000), a buccal mucoperiosteal flap was reflected, and buccal bone removal (bone guttering) and/or tooth sectioning under copious irrigation with sterile normal saline and tooth extraction were followed by a thorough irrigation of the tooth socket and suturing the flap with 3/0 black silk suture.

The duration of the surgery was recorded in minutes, starting from the incision to the end of the last suture. Antibiotics and analgesics were prescribed for all the patients who were instructed for postoperative care. The sutures were removed after 7 days. Postoperative complications, if present, were registered and managed accordingly.

The investigated data of the patients were demographic data, including age (the patients were divided according to their age into those who were $\leq 20$ years, 21-30 years, and those $>30$ years of age) and gender, radiographic data including the impacted tooth angulation as classified by Winter and the depth of impaction and the relation with the ramus of the mandible according to the Pell and Gregory classification, and clinical data including the state of eruption of the impacted teeth. These factors were evaluated for association with the duration of surgery. Due to its retrospective nature, ethical approval of the Institutional Review Board was not required and the privacy of all the patients in this study was maintained.

Statistical analysis was performed using GraphPad Prism version 6 for Windows (GraphPad Software, La Jolla, California, USA). Descriptive analysis included percentages and mean \pm SD. Student's t-test was used to compare means between two groups, while for comparing the means among three or more groups for statistical significance, ANOVA test was used.

Ethical approval of the Institutional Review Board was not required due to the retrospective observational nature of this study. All procedures performed in this study were in accordance with the ethical standards of the Institutional and/or National Research Committee, and the privacy of all the patients was maintained.

\section{RESULTS}

This retrospective study included 40 consecutive patients with unilateral impacted mandibular third molars. The study sample consisted of $20(50 \%)$ males and $20(50 \%)$ females, and the age range was from 17 to 37 years with a mean $\pm \mathrm{SD}$ of $23.4 \pm 5.02$ years.

The duration of surgery $( \pm S D)$ in all the patients ranged from 10 to 40 minutes with a mean of $25.8 \pm 8.56$ minutes. With respect to age groups, the duration of surgery was the longest in patients who were older than 30 years of age, while it was the shortest in patients $\leq 20$ years of age, but the difference among the groups was statistically not significant at $\mathrm{p}<0.05$ (Table 1 ).

The duration of surgery was longer in females than in males with a statistically not significant difference at $p<0.05$ (Table 1). With respect to the angulation of teeth, the results are summarized in Table 2 . The difference in duration among the groups was statistically not significant $(p<0.05)$.

In the first category of Pell and Gregory classification (positions I-III), the results revealed that the difference among the groups was statistically not significant $(\mathrm{p}<0.05)$. While with respect to the second category (classes I-III), the duration of surgery was significantly longer in class II than in class $1(p<0.05)$. To note is that none of the patients had class 3 ramus relationship (Table 2).

Unerupted teeth were associated with a longer duration of surgery than that of partially erupted teeth. The difference was statistically significant at $\mathrm{p}<0.05$ (Table 3 ). Minor complications of postoperative inflammatory response, which included pain, swelling, and limitation of mouth opening, were seen in all the patients and these subsided within 3 to 7 days after surgery.

Table 1: Duration of surgery in relation to demographic variables

\begin{tabular}{llll}
\hline Demographic data & $n(\%)$ & Mean time/min $\pm S D$ & $p$-value \\
\hline Age groups & & & \\
$\leq 20$ & $12(30)$ & $22.58 \pm 5.47$ & $0.217^{\mathrm{a}}$ \\
$21-30$ & $23(57.5)$ & $26.91 \pm 9.81$ & \\
$>30$ & $5(12.5)$ & $30.4 \pm 11.54$ & \\
Sex & & & \\
Male & $20(50)$ & $24.7 \pm 8.58$ & $0.176^{\mathrm{b}}$ \\
Female & $20(50)$ & $27.4 \pm 9.64$ & \\
\hline
\end{tabular}

${ }^{\mathrm{a} A N O V A}$ test; ${ }^{\mathrm{b}}$-test 
Table 2: Duration of surgery in relation to the radiographic variables

\begin{tabular}{lllll}
\hline Radiographic data & $n(\%)$ & $\begin{array}{l}\text { Mean time/ } \\
\text { min } \pm S D\end{array}$ & $p$-value \\
\hline Angulation & 21 & 52.5 & $24.71 \pm 9.89$ & $0.190^{\mathrm{a}}$ \\
Mesioangular & 9 & 22.5 & $30.33 \pm 5.17$ & \\
Horizontal & 6 & 15 & $21.33 \pm 4.18$ & \\
Vertical & 4 & 10 & $28 \pm 9.09$ & \\
Distoangular & & & & \\
Pell and Gregory (A-C) & 10 & 25 & $22.7 \pm 4.55$ & $0.324^{\mathrm{a}}$ \\
A & 27 & 67.5 & $27.22 \pm 9.77$ & \\
B & 3 & 7.5 & $23.3 \pm 2.9$ & \\
C & & & & \\
Pell and Gregory (1-3) & & & & \\
1 & 20 & 50 & $21.9 \pm 6.66$ & $0.0013^{* b}$ \\
2 & 20 & 50 & $29.7 \pm 8.59$ & \\
\hline
\end{tabular}

${ }^{a}$ ANOVA test; ${ }^{\text {t-test; }}{ }^{*}$ significant; ${ }^{\dagger}$ none of the patients had class 3 ramus relationship

Table 3: Duration of surgery in relation with the state of eruption

\begin{tabular}{llll}
\hline Clinical data & $n(\%)$ & Mean time/min $\pm S D$ & $p$-value \\
\hline State of eruption & & & \\
Partially erupted & $24(60)$ & $24.58 \pm 6.30$ & $0.04^{* a}$ \\
Unerupted & $16(40)$ & $30 \pm 7.52$ & \\
\hline${ }^{*}$ Significant; ${ }^{\text {at-test }}$ & & &
\end{tabular}

Only two patients (5\%) had dry socket postoperatively. Both patients were females, and treatment consisted of a thorough irrigation of the socket with saline solution and light packing with iodoform gauze that was replaced every 2 days, and they were asymptomatic within a week.

\section{DISCUSSION}

Third molar surgery constitutes a significant portion of the surgical procedures performed by oral and maxillofacial surgeons and is an important activity at dental surgery clinics. ${ }^{15}$ Various methods of assessment of the anticipated difficulty of surgical extraction of impacted mandibular third molars have been proposed using both radiographic and nonradiographic parameters, such as models set forth by Winter, ${ }^{9}$ Pell and Gregory, ${ }^{10}$ Pederson, Macgregor, and the WHARFE (Winter's classification, height of the mandible, angulation of second molar, root shape and morphology, follicle development, and exit path) classification/ scoring systems. ${ }^{16}$ The use of radiographs to predict the difficulty of surgical extraction of impacted teeth has been questioned by Chandler and Laskin ${ }^{17}$ who argued that the best way to determine the complexity of the surgery is at the time of surgery.

The duration of surgery is generally regarded as the gold standard for the measurement of surgical difficulty of impacted mandibular third molar extraction, ${ }^{12}$ while other studies also used total intervention time as an index of surgical difficulty. ${ }^{14}$ Renton et $a{ }^{13}$ found that the definitive measure of operative difficulty was the actual surgical experience recorded at the end of surgery by the operator which they reported to strongly correlate with the operating time. In this study, various factors that may influence the operative duration of surgical extraction of impacted mandibular third molars as an indicator for the surgical difficulty were investigated.

The results of this study are in keeping with most previous reports in that patients in their third decade predominate, although it is reported that generally female patients seek extraction of lower third molars more than males, with reported male:female ratio ranging from 1:1.15 to $1: 3 .^{12-15,18}$

The mean duration of surgery recorded in this study (25.8 \pm 8.56 minutes) is within the range of means reported by other authors (7.57-105 minutes) who alluded to various factors that explain this variation, including the experience of the surgeon, types of anesthetic technique, speed and sharpness of bone cutting instrument, and the overall facilities employed. ${ }^{12,13}$

With respect to the demographic factors investigated in this study, age did not significantly correlate with the duration of surgery despite the fact that surgical extraction of impacted lower third molars of patients older than 30 years of age required longer time than the other two groups and that patients younger than 20 years needed less time for their surgeries. This is in agreement with other reports, ${ }^{15,19}$ which showed that there was no statistical association between the duration of surgery and the age of patients. On the contrary, in their systematic review and meta-analysis, Akadiri and Obeichina ${ }^{16}$ assumed age as the principal demographic variable to be considered contributing to the surgical difficulty, and a similar observation was also made elsewhere. ${ }^{13,14}$ This relationship between increased age and increased extraction difficulty is established in the literature which is attributed to the increased bone density and calcification with age, making it less flexible and less likely to bend under forces of tooth extraction. ${ }^{1,16}$

Many studies showed that gender was not a significant factor in determining the difficulty of extraction, 9,12,14,15 and the current study found a statistically nonsignificant association between the duration of surgery and gender, although the recorded duration was longer in females than in males. Renton et $\mathrm{al}^{13}$ reported gender as a significant factor in determining the operative duration, but they identified male gender to be associated with longer duration of surgery in univariate analysis, while in multivariate analysis, gender was not a significant factor. Although male gender is reported to be associated with increased difficulty of extraction on account of increased bone density, ${ }_{1}^{13}$ it is reported that females are more prone to experience postoperative complications after impacted 
third molar surgery. ${ }^{2}$ Nakagawa et al $^{20}$ identified the female gender as a risk factor because of the mandible lesser bone thickness. On cross-checking the data, in the current study, it was found that 12 of the 16 patients $(75 \%)$ who had unerupted teeth were females. In this study, the state of eruption of teeth was found to be a statistically significant predictive factor in determining the duration of surgery being longer in unerupted teeth. This could explain the longer duration of surgery associated with female patients, which could be attributed to the smaller size of the mandible in females as compared with males, and hence, the less available space for the eruption of the third molars.

According to Winter's classification, mesioangular spatial relationship was the most commonly encountered, while distoangular impacted teeth were the least commonly identified in this study. Similar results were reported by Obimakinde et al, ${ }^{12}$ whereas Renton et $\mathrm{al}^{13}$ reported mesioangular impacted teeth to be the most common and horizontal impaction to be the least common in their study. Vertically impacted lower third molars were the most common in other studies. ${ }^{15}$ In this study, horizontally impacted teeth were associated with the longest operative duration, in descending order, followed by distoangular, mesioangular, and vertically impacted teeth. Other studies ${ }^{7,13,15}$ also reported horizontally impacted teeth to be a predictive variable in increasing the surgical difficulty. Pederson's difficulty index considers distoangular impacted lower third molars to be the most difficult in extraction followed, in descending order, by vertical, horizontal, and mesioangular impaction. 7,14 The results of this study show that the angulation of impacted teeth is not a statistically significant predictive factor in determining the operative duration. This is in keeping with other studies, ${ }^{7,13,14}$ yet in contrast with other reports ${ }^{12}$ the reported angulation of teeth is significantly associated with surgical difficulty.

In the current study, depth of impacted teeth as classified by Pell and Gregory was shown to be not a significant factor in determining the duration of surgery, whereas the ramus relationship was a statistically significant factor. Other studies ${ }^{7,15,12}$ showed depth and ramus relationship to be positive predictive factors of surgical difficulty. Renton et $\mathrm{al}^{13}$ found that the depth of application is a significant factor in determining the duration of operation, and hence, the surgical difficulty in univariate and multivariate analysis levels. In one study, ${ }^{21}$ Pell and Gregory ${ }^{10}$ classification was deemed unreliable in predicting the surgical difficulty of impacted lower third molars.

The main limitations of this study are the small sample size and the retrospective methodology.

\section{CONCLUSION}

Despite its limitations, this study identifies state of eruption and ramus relation to be significant predictive factors, whereas other investigated factors, namely age of patient, sex, angulation of teeth, and depth of impaction, were found to be not significant in determining the duration of surgery and hence, the difficulty of extraction.

\section{CLINICAL SIGNIFICANCE}

The duration of surgical extraction of impacted mandibular third molars can be considered as an indicator for the difficulty of surgical extraction. Difficult surgical extraction of impacted mandibular third molars can be anticipated in clinically unerupted teeth and those with deep ramus relationship.

\section{REFERENCES}

1. Hupp JR, Ellis E III, Tuker MR. Contemporary oral and maxillofacial surgery. 6th ed. St. Louis (MO): Mosby; 2014.

2. Varghese KG. A practical guide to the management of impacted teeth. New Delhi: Jaypee Brothers Medical Publishers (P) Ltd; 2010.

3. Lytle JJ. Indications and contraindications for removal of the impacted tooth. Dent Clin North Am 1979 Jul;23(3):333-346.

4. Andreasen JO, Petersen JK, Laskin DM. Textbook and color atlas of tooth impactions: diagnosis, treatment, prevention. Copenhagen: Munksgaard; 1997.

5. Suri L, Gagari E, Vastardis H. Delayed tooth eruption: pathogenesis, diagnosis, and treatment. A literature review. Am J Orthod Dentofacial Orthop 2004 Oct;126(4):432-445.

6. Juodzbalys G, Daugela P. Mandibular third molar impaction: review of literature and a proposal of a classification. J Oral Maxillofac Res 2013 Apr-Jun;4(2):e1.

7. Yuasa H, Kawai T, Sugiura M. Classification of surgical difficulty in extracting impacted third molars. Br J Oral Maxillofac Surg 2002 Feb;40(1):26-31.

8. Bui $\mathrm{CH}$, Seldin EB, Dodson TB. Types, frequencies, and risk factors for complications after third molar extraction. J Oral Maxillofac Surg 2003 Dec;61(12):1379-1389.

9. Winter GB. Principles of exodontia as applied to the impacted mandibular third molar: a complete treatise on the operative technique with clinical diagnoses and radiographic interpretations. St. Louis (MO): American Medical Book Company; 1926.

10. Pell GJ, Gregory GT. Impacted mandibular third molars: classification and modified technique for removal. Dent Digest 1933 Sep;39(9):330-338.

11. Killey HC, Kay LW. The impacted wisdom tooth. London: E\&S Livingstone Ltd.; 1965.

12. Obimakinde OS, Akinpelu AM, Obimakinde AM. Risk indicators of operative difficulty of impacted mandibular third molar in a Nigerian Tertiary Hospital. Open Access Sci Rep 2012 Sep;1(7):354.

13. Renton T, Smeeton N, McGurk M. Factors predictive of difficulty of mandibular third molar surgery. Br Dent J 2001 Jun;190(11):607-610.

14. Gbotolorun OM, Arotiba GT, Ladeinde AL. Assessment of factors associated with surgical difficulty in impacted 
mandibular third molar extraction. J Oral Maxillofac Surg 2007 Oct;65(10):1977-1983.

15. Carvalho RW, do Egito Vasconcelos BC. Assessment of factors associated with surgical difficulty during removal of impacted lower third molars. J Oral Maxillofac Surg 2011 Nov;69(11):2714-2721.

16. Akadiri OA, Obiechina AE. Assessment of difficulty in third molar surgery-a systematic review. J Oral Maxillofac Surg 2009 Apr;67(4):771-774.

17. Chandler LP, Laskin DM. Accuracy of radiographs in classification of impacted third molar teeth. J Oral Maxillofac Surg 1988 Aug;46(8):656-660.

18. Bello SA, Adeyemo WL, Bamqbose BO, Obi EV, Adeyinka AA. Effect of age, impaction types and operative time on inflammatory tissue reactions following lower third molar surgery. Head Face Med 2011 Apr;7:8.

19. Susarla SM, Dodson TB. Estimating third molar extraction difficulty: a comparison of subjective and objective factors. J Oral Maxillofac Surg 2005 Apr;63(4):427-434.

20. Nakagawa Y, Ishii H, Nomura Y, Watanabe NY, Hoshiba D, Kobayashi K, Ishibashi K. Third molar position: reliability of panoramic radiography. J Oral Maxillofac Surg 2007 Jul;65(7):1303-1308.

21. García AG, Sampedro FG, Rey JG, Vila PG, Martin MS. Pell-Gregory classification is unreliable as a predictor of difficulty in extracting impacted lower third molars. Br J Oral Maxillofac Surg 2000 Dec;38(6):585-587. 